\title{
LA DERROTA DE LOS POBLADORES: CUEVAS, ZURITA, FORMOSO ${ }^{1}$
}

The defeat of the villagers: Cuevas, Zurita, Formoso

Magda Sepúlveda Eriz*

\section{Resumen}

Los pobladores constituyeron uno de los actores urbanos más importantes de la segunda mitad del siglo XX en Chile. Los poetas José Ángel Cuevas, Raúl Zurita y Christian Formoso abren su trabajo a las voces y al mundo de los pobladores. Pero lo hacen cuando los pobladores, en tanto agentes de cambio, están extinguiéndose. Este artículo analiza cómo la escritura de estos tres poetas hurga en la derrota de estos actores sociales durante la transición chilena.

Palabras clave: José Ángel Cuevas, Raúl Zurita, Christian Formoso, poesía chilena, transición, pobladores.

\section{Abstract}

Shantytown inhabitants were one of the most important urban actors in the second half of the twentieth century. José Ángel Cuevas, Raúl Zurita and Christian Formoso open their work to the voices and the world of these people. But when the poets do this, the agents of change are already becoming extinct. The writing of these three poets digs into the defeat of villagers during the transition.

Key words: José Ángel Cuevas, Raúl Zurita, Christian Formoso, chilean poetry, Transition, villagers.

Caluga o menta (1989) de Gonzalo Justiniano, puesta en cartelera en 1990, es una película de los inicios de la transición chilena que representa el estado de los pobladores tras la dictadura. La película construye una representación de la vida de los jóvenes en una población periférica de Santiago. Se trata de jóvenes desempleados que roban y obtienen algún dinero con la venta ilegal de marihuana. El tiempo laxo de la película se corresponde con la aburrida vida que transcurre en el erial, sitio que ellos toman como un balneario. En medio del polvo, ellos instalan sillas de playa, beben cerveza y escuchan música. Así, los jóvenes esperan que llegue la noche y la oscuridad y, con ellas, el tiempo propicio para robar. La representación de la devastación de los sectores populares fue una figuración constante durante la transición (1989-2009), ${ }^{2}$ especialmente en la poesía chilena.

\footnotetext{
${ }^{1}$ Este artículo forma parte de mi investigación "La poesía chilena de la promoción de los 90: derrota y pérdida de referencias nacionales", financiada por la Dirección de Arte y Cultura de la Pontificia Universidad Católica de Chile.

${ }^{2}$ Sigo a Rafael Otano (2006) al considerar que la transición se inicia con la caída de la dictadura (1989) y finaliza cuando se acaban los gobiernos de la Concertación de partidos por la democracia, lo que sucedió el año 2009.
} 


\section{Magda Sepúlveda}

A su vez, un conjunto importante de la poesía escrita por distintas promociones, está dedicada al "ex Chile", ese país de pobladores que dejó de existir, pero cuya forma se recuerda continuamente en la poesía escrita durante la transición. La alusión a los pobladores durante la posdictadura está en poetas de la promoción de los 60, como José Ángel Cuevas; de los 70, como Raúl Zurita; o de los 90, como Christian Formoso que dan cuenta del fin de un ideal político que unía a pobladores y estudiantes en pos de un nuevo amanecer. El itinerario de esa voluntad constructiva puede leerse, ya, en el disco $L a$ población (1972) de Víctor Jara. Detengámonos brevemente en este texto para entender el interés sobre la población que se dio posteriormente en la poesía chilena publicada durante la transición.

El long play La población de Víctor Jara está inspirado en un hecho verídico, como fue la toma de unos terrenos en Cerro Navia (1967) que dio origen a la población Herminda de la Victoria. ${ }^{3}$ En el disco, diversos personajes de la toma van relatando la historia. Por ejemplo, el campesino que vino a la ciudad sin tener más seguridad que la confianza en la urbe como espacio de desarrollo económico: "Y mis manos son lo único que tengo/ y mis manos son mi amor / y mi sustento./ No hay casa donde llegar, / mi paire y mi maire están / más lejos de este barrial / que una estrella" (Jara 3). Frente al saber letrado y al capital económico, dos instancias movilizadoras de la urbe, este campesino sólo tiene sus manos, con las cuales espera ganarse la vida y obtener progreso económico. Junto al campesino participan, en la toma, otros marginados de la ciudad, como las prostitutas, llamadas "coliguillas" que tienen también voz: "A'onde vaiga, a'onde vaiga la gente / llegamos nosotras, /dispuestas a lo que sea, /sea fiesta o sea rosca" (Jara 5). La integración entre diversas subjetividades populares que se da en La población tiene un correlato en el aspecto formal del disco, donde es posible escuchar tonadas, cuecas y marchas (Lascar, 2010), entre otros ritmos que dan cuenta de las melodías que acompañan a distintas identidades sociales.

Víctor Jara elabora una continuidad entre pobladores, patria y proyecto político socialista. En "Marcha de los pobladores", su voz apela considerando este metarrelato: "Poblador, compañero poblador, / por los hijos, por la patria y el hogar. /

\footnotetext{
${ }^{3}$ La primera "toma" chilena ocurrió en 1957 en la comuna de Pedro Aguirre Cerda, Santiago. Los pobladores lograron quedarse en el sitio, por lo cual lo denominaron población "La Victoria". De acuerdo con los datos que proporciona Garcés (2002) esta toma fue realizada por habitantes provenientes del Zanjón de la Aguada que estaban cansados de ser mordidos por las ratas en la noche y que quedaron aún más desprovistos tras el incendio de una parte del asentamiento callampa en 1956. El cardenal Caro negoció para que se les permitiera quedarse en los terrenos tomados de la ex Chacra la Feria. Se daba inicio, así, al movimiento de los pobladores que ocuparía un sitio destacado en el acontecer nacional hasta fines de la dictadura militar. Diez años después, el 16 de marzo de 1967, ocurre la toma que canta Víctor Jara. En ella muere la bebé Herminda, de ahí que la población tome su nombre "Herminda de la Victoria". Sobre esta "toma" existe el documental Herminda de la Victoria (1968) realizado por Douglas Hubner.
} 
Poblador, compañero poblador, / ahora la historia es para ti, / con techo, abrigo y pan, /marchemos juntos al porvenir / Poblador, compañero poblador, / por las banderas del gobierno popular. / Poblador, compañero poblador / por los hijos, la patria y el hogar" (Jara 7). La integración que canta Víctor Jara se enmarca dentro de una idea propia de los años 60, a saber, que la mejor forma de salir de la marginalidad era mediante la iniciativa de "promoción popular", elaborada por el sacerdote jesuita belga Roger Vekemans, que vivió en Chile entre 1957 y 1970. La estrategia de la "promoción popular" consistía en que los propios grupos desfavorecidos elaboraban sus peticiones al Estado, previa organización interna de ellos. Vekemans la explica así: "Desde el punto de vista de los grupos marginales es obvio que superar la desintegración interna y llegar a la organización, necesitará de un nuevo contenido valórico" (Vekemans, 1969:90). La conciencia organizativa deseada por Vekemans se cumple a cabalidad en la población imaginada por Víctor Jara. Esa construcción, que potencia al poblador como actor social dinámico y fuerza de cambio, fallece en la poesía de la posdictadura.

\section{EL FIN DE LOS POBLADORES: JosÉ ÁNGEL CUEVAS}

La fuerza del poblador como actor social, representada por Víctor Jara, caduca en la poesía de José Ángel Cuevas (1944). En cuatro de sus libros escritos durante la transición, a saber Proyecto de País (1994), Poesía de la comisión liquidadora (1997), Diario de la ciudad ardiente (1998) y Restaurant Chile ${ }^{4}$ (2005) elabora la llegada de la transición como la muerte de los pobladores. Por ello, el poeta dedica Restaurant Chile al "pueblo de Chile que ya dejó de existir" (2005:5). Ya en una entrevista dada a Cherrie Zalaquett, en 1989, el autor indicaba cómo había cambiado la concepción de pueblo: "Admirábamos al pueblo. Hoy sé que es un concepto medio viejo; que está lleno de lumpen y delincuencia, pero lo veíamos como gente noble" (www.letrasS5.cl). Ese antiguo pueblo que "unido jamás será vencido", donde los obreros se oponían a una autoridad injusta - llámese tirano o jefe explotador - es el motivo del réquiem elaborado por Cuevas.

En Cuevas, los pobladores y el sujeto (líder) que los apoyó están derrotados. La voz del que ha sido marginalizado recibe distintos nombres en la creación de Cuevas. Efrén Sepúlveda Fica es quien habla en Proyecto de País. Denuncia a aquellos como "ese, el que perdió la memoria de sí" (1994:3), refiriéndose a los retornados que olvidaron sus antiguos idearios y que aspiraron a un mundo que

ya no será llamado popular ni cruzarán lanchas los canales se irán lejos los caballos y todo será una pura mancha.

La Fosa común, le dirán (12).

\footnotetext{
${ }^{4}$ Restaurant Chile es una antología que incluye poemas desde "El mundial del 62" hasta algunos de Proyecto de País. Y, además, incorpora nuevos textos.
} 


\section{Magda Sepúlveda}

Proyecto País es una polémica abierta contra los ideales modernizadores que trajeron los retornados. Dado que ese nuevo proyecto nacional estaba hecho sobre el olvido, Efrén usa "hospital Chile" como una metáfora espacial para denominar al país "Yo, Efrén L. Sepúlveda Fica / enfermo como estoy / en cama / pero/ en mi sano juicio declaro / este infinito Hospital / Chile restaurante" (1994:12). En Poesía de la Comisión Liquidadora, quien habla es Mario Maguncia, un alcohólico: "este pobre infeliz y bebedor / de Mario Maguncia" (1997:9). Maguncia denuncia la transacción que efectuaron de sus ideales populares los izquierdistas, lo que puede soportar sólo en la medida que se evade a través del alcohol, al igual que se evade ese pueblo con que sueña

los trabajadores no se conocen a sí mismos

no hablan con nadie,

están ahí no más,

tomando vino acostados en el suelo

con sus herramientas / viandas secas

frente a la pantalla

Los trabajadores / fueron ensoñación de algo que ya

no se recuerda / los trabajadores están ahí / solos

olvidados / apocados frente a sus herramientas /

mohosas y viejas (1997:16).

El olvido de los sectores populares no sólo los afecta a ellos mismos, sino también al grupo letrado que creyó en ese metarrelato. ${ }^{5}$ En Diario de la ciudad ardiente, los amigos del hablante están deprimidos: "Jorge está tomando diazepam, Líber brozepam, yo lorazepam, estamos mal" (1998:107). Un conjunto de ciudadanos queda extraviado y deprimido al perderse la narrativa sobre los pobladores.

El metarrelato sobre los pobladores es abandonado y en su lugar surge el metarrelato del individuo, que solitario, logra el éxito económico siendo satirizado por Cuevas: "Mi padre me dijo: no te preocupís de nada / solo de ti mismo, / porque cuando caigas en la mierda / nadie te va a tender una mano" (1994:34). En el nuevo sistema neoliberal la regla es el rompimiento con la comunidad, práctica que resiente Efrén

Oiga, compañero,

Eh, quién es compañero / de nadie

Aquí / podría morir

tirado en el suelo / nadie va a decir nada

no te metas en lo que no te importa,

Eh, compañero (1994:26).

De la comunidad se pasó a la familia considerada como una isla: "Y los nuevos ideales de este sistema económico: "De no haber un mundo feliz / luchad

\footnotetext{
${ }^{5}$ Lyotard define el concepto de metarrelato en atención a lo que produce una legitimidad en el conocimiento, en la libertad y la noción de tiempo, entre otras variables de la vida humana (1984). 
por una familia feliz / un matrimonio feliz" (1994:42). Sobre este aspecto, Soledad Bianchi ha dicho que "la poesía de José Ángel Cuevas gira en torno a un núcleo básico que es su real obsesión: la pérdida de la comunidad" (169). Para Cuevas, la forma individualista de vivir es la gran derrota que significó la transición.

Los hablantes creados por Cuevas están acompañados por otros derrotados y no por los retornados que creen en el neoliberalismo, ni tampoco por los pobladores que tienen ahora otro ideario. Los pobladores posgolpe, descritos por Cuevas, rechazan a estos letrados derrotados y no creen posible una unidad con quienes no pertenecen a su hábitat. Los pobladores amenazan incluso a esos derrotados

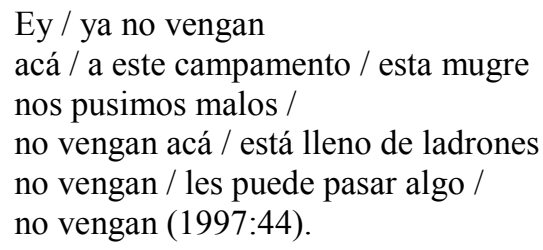

Los nuevos pobladores de Cuevas han levantado la amenaza y la fuerza delictiva como patrón de dignidad. Esa violencia los saca de su condición de vencidos y los deja a la par de los vencedores. Pero ellos no tienen ya ninguna identificación con la patria como en el metarrelato hilvanado por Víctor Jara.

El relato sobre los pobladores que muere en la transición, en Cuevas está caracterizado por un cambio en las formas de diversión. Cuevas se detiene en imaginar la fiesta pre-73, en la que se embanderaba la calle y se sentaba en la mesa con los amigos y vecinos, fiesta que se clausura con el golpe y que Cuevas desea volver a tener, incluso en plena dictadura "Luchito Barrios canta "Humo y Licor", y Los Ángeles Negros, "Cómo quisiera decirte". Hay una botella de vino puesta, pronto se viene Navidad, el barrio debería llenarse de ampolletas, jarros, cola de mono y pan de pascua picado, fuentes de ensalada y papas con mayonesa. Cajones con camioncitos, muñecas que muevan los ojitos, cocinas, pitos" (1998:18).

Para Cuevas, el periodo pregolpe es metaforizado como una "fiesta" cuya particularidad es su contexto ciudadano. En ella, el espacio pasa a ser un aspecto fundamental, la fiesta ocupa el espacio público y es intergeneracional. Sobre la convivencia de lo local y lo trasnacional en la música de esta fiesta, María José Barros sostiene que: "El rock implicó no sólo una revolución en el ámbito musical, sino también a nivel de valores: era signo de libertad, juventud, sexualidad sin tabúes, viajes y rebeldía hacia los padres. Por lo anterior, el sujeto combinó sin contradicciones el poncho con el jeans y la casaca de cuero, el Che con Elvis Presley y la Peña de los Parra con los Beatles" (Barros, 2009:6). De esta manera, la fiesta pre-73, donde el poblador es un compañero de alegría, es un espacio de integración de diversas tradiciones que se movilizaban hacia el cambio social. 


\section{Magda Sepúlveda}

Con la dictadura se inicia la mala fiesta, la que ocurre en lugares oscuros, ya sea en el centro de la ciudad o en las poblaciones. En el centro de la ciudad, la mala fiesta creada durante la dictadura era el topless: "Con el comienzo de los topless, en cualquier lugar de la ciudad, (un) par de cortinas, un subterráneo, una exoficina de comercio exterior se transforman en topless, donde, desde las once de la mañana (se llenaba) de vendedores de las nuevas empresas de previsión obligatorias y salud privada" (1998:99). En "la Mala Fiesta" (1994:14) de las poblaciones hay consumo de drogas: "Da pena ir a las poblaciones, ver bailando rap a los muchachones bufoneando con el gorro echado para atrás, loco, sabí que na' que ver, vamos a hacer unas movías loco, cachaí o no? algo pa' la angustia, un copetito, un join" (1998:100). El poblador ha pasado de compañero de fiesta a delincuente. Esas nuevas diversiones ya no están asociadas a la cultura de la comida popular

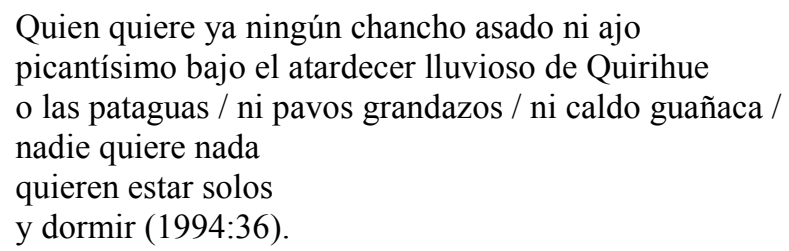

El entierro del pueblo es, en esta poesía, el exterminio de una forma de diversión, que poseía formas de alimentarse y de cantar reconocibles. Sobre el aspecto de la crisis de lo popular en Cuevas, Naín Nómez ha planteado que en Proyecto País está la clausura del sueño bucólico, vale decir, la imposibilidad de retomar el imaginario del campo exaltado por De Rokha y formular con ello una arcadia que exorcice los traumas del presente y nos libere de la chatura de los nuevos sueños del presente (Nómez, 2010:192). Esa chatura está protagonizada por un nuevo actor, que reemplazó al poblador, como es el consumidor. Para el consumidor ya no es necesario sindicalizarse para lograr mejores bienes, basta con endeudarse con la tarjeta de crédito
ahí van las poblaciones
en bloque pegadas /unas con otras
(p)romiscuo / arrastrándose psch psch / mamita
Papito / Ey, y sacan tele / y sacan video a puro ver /
n'a que ver que saquen tele / los hijos de los hijos
muertos / punk armados / raps rapados
están todos locos / en las poblaciones (1997:19).

Cuevas reproduce la oralidad popular, enfatizando el orgullo de ese habla que ya no aspira a simularse letrada. Los nuevos pobladores son los punks y los skins que Cuevas rechaza. Tal como en "Fervor de Buenos Aires" (1923) de Borges, Cuevas penetra en el arrabal, pero donde el escritor argentino se reencuentra con su infancia calmada, el poeta chileno aprecia el lugar del 
autoexterminio. Los nuevos jóvenes no tienen un metarrelato revolucionario, sólo esperan en la esquina del block y al son de un reggeaton que el día pase y llegue la noche para delinquir.

\section{LA POBLACIÓN FUE UN SUEÑO: RAÚL ZURITA}

Así como Cuevas representa el fin de los pobladores como fuerza de cambio, un poeta de los 70 acude a otra enunciación. Raúl Zurita en La vida nueva (1993) inventa para los pobladores el lenguaje de los sueños. Zurita (1950) hace hablar a los pobladores desde su mundo onírico. Su fórmula retórica tiene que ver con el testimonio, es decir, siguiendo a Beverly (2004) hay una voz básica que introduce el habla del subalterno, generando un texto que anula la oposición ficción/no ficción. Esta voz que facilita el habla del que tiene bloqueado los accesos públicos para enunciar, es la de una periodista. Zurita emplea las grabaciones del diálogo entre una entrevistadora y los pobladores; y a la vez crea para sí mismo la voz de un testigo que vio las ocupaciones de terrenos. Con estas voces, Zurita selecciona, corta y arma los poemas del libro y de esta forma crea la ficción de una enunciación testimonial que le permite poner un valor de documento al poemario.

La estrategia del testimonio creada por Zurita permite traer a la vida a los pobladores asesinados durante la dictadura. Para cada uno de ellos - y de ellasel poeta crea una voz particular. Los primeros testimonios corresponden a pobladores que participaron en la ocupación de terrenos que dio origen al campamento Raúl Silva Henríquez, toma que se efectuó en 1983, en plena dictadura militar. ${ }^{6}$ El poeta asume el rol de testigo de esos hechos y de la represión posterior miles de banderas flameaban sobre las casuchas de cartón y plástico del campamento Raúl Silva Henríquez, amontonados, los cuerpos de sus moradores parecían fundirse en la penumbra entre los guitarreos y los extraños zumbidos de las radios portátiles (1993:16).

En esta visión del poeta se superponen dos tiempos: el de la toma misma con sus banderas y sus guitarreos; y el otro, el de la represión, con sus asesinatos y los cuerpos de los pobladores amontonados. Como en el cine, estas dos situaciones se yuxtaponen ante el ojo congelado de quien imagina y relata el crimen. La dictadura fue feroz en las poblaciones. Para el historiador Mario Garcés "Los dos grandes protagonistas colectivos del siglo XX fueron el movimiento obrero y el movimiento de pobladores" (Garcés, 2002:5). Debido a este protagonismo, podemos entender la represión violenta que sufrieron. De los testimonios, el autor selecciona la parte de los sueños y no borra la marca que

\footnotetext{
${ }^{6}$ Durante la dictadura se efectuó otra "toma", la que dio origen al poemario La bandera de Chile (1981) de Elvira Hernández. La poeta desarrolla una escritura vanguardista (motivada en parte por la censura) en la que hace converger el símbolo nacional la bandera, con el problema del territorio (población La Bandera) y con el género que llevó adelante la ocupación, a saber, las mujeres pobladoras.
} 


\section{Magda Sepúlveda}

indica que hay una entrevistadora, buscando subrayar así el significante propio del documento etnográfico. La periodista de La vida nueva le cede la voz a Alamiro Núñez, un poblador que fue perseguido

Yo solamente sueño que me persiguen. Ese es mi problema, señorita. De un tiempo a esta parte lo único que sueño es que me persiguen y son siempre carabineros o gente de civil. Ahora, en el sueño mío, yo (...). Iba por una calle llena de piedras que se hacían más filosas y de pronto estaba corriendo por un campo arado, como cuando era niño, porque de allá vengo (1993:17).

Alamiro parte relatando su huida de un allanamiento masivo, represión que consistía en obligar a todos a salir de sus casas, separando a los hombres a un lado y a las mujeres en el otro. Todos debían desprenderse de sus zapatos y quedarse en ropa interior, mientras las fuerzas militares se llevaban a los que les parecían sospechosos. La vía por la que huye Alamiro se fusiona con un camino de su origen campesino. Y es la parte de esos sueños, ligados a un origen de cercanía con la tierra, lo que Zurita busca rescatar. A partir de los años 50, viene produciéndose la migración campo-ciudad. Los campesinos, cansados de la falta de movilidad social que se da en el campo chileno, ${ }^{7}$ ponen su esperanza en la ciudad como espacio moderno. Pero los que sabían manejar el arado no llegan al centro cívico, sino a los bordes de la ciudad, a los conventillos y a las poblaciones.

Zurita va trazando a través distintas voces la composición de la población Raúl Silva Henríquez. Para Oscar Galindo, "La vida nueva es una polifonía textual (donde el) poeta (es) definido como recolector de las voces de la colectividad" (2002:210). Junto a los alzados de procedencia campesina, Zurita posiciona también a los pobladores de origen mapuche que pusieron su esperanza en la ciudad, pero vivieron en ella la discriminación étnica y luego la represión. Entonces decidieron volver a sus tierras ancestrales. El testimonio, ahora, es de Carlos Coñuepán: "Somos todos pobres, muy pobres, señorita, por eso nos vinimos (...). Así lo empecé a soñar: venían tres figuras, pero eran como de un trote de bestias con sus caras mirándome. El último era el cacique, pero él venía con forma humana. Se me allegó bien y me dijo que estaba sufriendo ahí, que tenía que irme de la capital. Me volví entonces en aire, en suspiros me fui hasta mi tierra de Mehuín" (18).

En este testimonio están convocados dos sueños: el de la ciudad como lugar de oportunidades económicas y el del retorno a las tierras ancestrales. Ninguno de los dos se hace realidad. El segundo sueño, la vida nueva para Coñuepán, es volver a unas tierras que la transición no defendió. Durante la posdictadura, el pueblo mapuche ha vivido en crisis permanente, producto de

\footnotetext{
${ }^{7}$ Gabriel Salazar y Julio Pinto analizan en Historia de Chile III, las condiciones de vida del campesinado chileno durante el siglo XX: "no existían relaciones de tipo salarial; los ritmos de trabajo dependían de los ciclos naturales" (2002:101). Por esto, ellos no estaban "integrados al consumo interno, como a la vida cultural y política del país" (2002:113).
} 
una nueva asolada sobre sus tierras. Ya no la de los españoles, sino la de la modernidad tecnológica que necesita un plus de producción nunca antes experimentado. Por eso, Mehuín - la tierra de Coñuepán - está amenazada. La empresa celulosa CELCO planifica construir un ducto para botar sus residuos en la caleta de Mehuín. Así, estos pobladores quedan en la derrota absoluta.

Los sueños de los pobladores han tenido la derrota por destino. Junto a ellos han perdido también los estudiantes. Para los universitarios, Zurita ya no usa el testimonio, sino la fórmula retórica de la inscripción en la lápida, mediante ella da los nombres y el lugar donde cada uno de ellos fue asesinado. Tal como en Cuevas, hay en La vida nueva un deseo de unidad entre el sujeto letrado y el poblador. Esa unidad venía estableciéndose desde los 60, donde parte importante de los universitarios comenzaron a comprender la situación de desigualdad social que vivía el país. Ya en 1963, Violeta Parra cantaba "Me gustan los estudiantes": "Me gustan los estudiantes / que marchan sobre la ruina / con las banderas en alto / va toda la estudiantina: / son químicos y doctores, / cirujanos y dentistas" (www.violetaparra.cl). La participación política de los estudiantes explica la represión de que fueron objeto, al igual que lo fueron los pobladores. Zurita crea para los estudiantes el capítulo "In memóriam Universidad Santa María (1967-1973)" (255) de La vida nueva. La Universidad Técnica Federico Santa María de Valparaíso tiene especial importancia para Zurita, pues allí estudió Ingeniería Civil. Además, las instalaciones de esta Universidad fueron usadas para interrogar y mantener detenidas a personas que venían, fundamentalmente, del barrio Los Placeres, de Valparaíso. La universidad también desalojó a los alumnos del internado, para que la guardia militar durmiera allí. Muchos detenidos fueron trasladados desde ahí a la Academia de Guerra Naval, donde se realizaba el interrogatorio implacable y por donde pasaron cerca de 1.500 personas. Los estudiantes que vivieron ese cruel derrotero son recordados por el poeta

Anotada la imagen que vuelve.

Nicho 1: hombres y países.

Anotado el nombre de una mujer:

Higinia Castro, estudiante.

Borrados todos del amor es el recuerdo.

Estará escrito un puerto, un mar, una universidad: Santa María.

Anotado el grito que vuelve.

Nicho 2: hombres y países.

En galpones de sueño se dice

José Poffalt, estudiante.

Se dice el océano y su inmensidad

inundando la mañana (259). 


\section{Magda Sepúlveda}

La estrategia de la voz enunciadora consiste en hacer volver su espanto como si fuera un testigo: "la imagen que vuelve" y "el grito que vuelve". La voz está en la escena del pasado, desde ahí "anota", vale decir, escribe. Cada personaje vuelve a la vida al ser nombrado. Por la letra de Zurita, los estudiantes y los pobladores, con la multiplicidad de sus procedencias, adquieren vida, "la vida nueva" que da el arte.

Zurita permite el testimonio de diversos pobladores asesinados durante la dictadura, para ello va poblando el espacio discursivo de sus distintas voces. En ello se asemeja a Víctor Jara que le daba voz a la mujer, al maestro carpintero y a todos los participantes de una toma. Pero Zurita se diferencia de Cuevas, pues no construye una representación para el presente de los pobladores durante la transición, imaginario que sí desarrolla Cuevas con el propósito de situar en ese tiempo la derrota de este actor social.

\section{LA FOSA DE LOS POBLADORES: CHRISTIAN FORMOSO}

Christián Formoso (1971) sigue en la línea de Zurita, en el sentido que hace hablar a los pobladores desde la fosa en que fueron depositados por la represión dictatorial. Pero Formoso va más lejos en el tiempo. Más bien, va más atrás en el tiempo. En El cementerio más hermoso de Chile (2008), Formoso traza una sintaxis que finaliza con los pobladores lanzados al mar por la dictadura, pero comienza con el exterminio de los primeros pobladores, los nativos de la zona patagónica.

Cada poblador lanzado al mar adquiere una voz particular en la poesía de Formoso. Cada uno de ellos recuerda el momento de su asesinato, pero con un lenguaje amoroso, donde víctima y victimario son un mismo cuerpo. De esta forma el muerto por fusilamiento ve, en sus asesinos, otros yo de sí mismo: "y escuché que yo decía ya andas en tomas y ya no sé qué más decía, pero entonces me vi de nuevo (y) veía mis manos enlazadas a las manos de ellos y con mi mano que estaba más cerca yo tomaba un fierro y hablaba y me decía que yo era el mismo enlazándolo todo. Y del fierro salía fuego que entraba en mi cabeza del otro yo mismo (y) entonces sentía que un llanto largo y un gemido muy corto salían a la distancia, y yo me decía a mis otros dos que yo no me iba a ninguna parte y me echaba tres disparos y luego me ponía una piedra en el pecho de ellos para no irme, y una ola me decía quédate porque alguien te va a destapar, y te van a poner otro nombre" (2008:314).

El poblador, que posteriormente pasará a ser un detenido desaparecido — pues su nombre se extraviará- observa que sus asesinos componen junto a él un solo cuerpo social. Esta voz más allá de la muerte es el imposible que crea Formoso. Y no sólo están más allá de la muerte, sino también más allá del odio.

El artificio de Formoso es hablar desde el cementerio de Punta Arenas y desde otros campos de inhumación cercanos. Desde cada tumba, desde cada osamenta, un cadáver se levanta y cuenta su historia. Es decir, para Formoso, la 
historia de la zona la poseen los que están enterrados. De ahí que Eugenia Brito indique que Formoso "hace posible una escritura en busca de una historia y de una historia que es la búsqueda de su ruina y la dotación del sentido" (www.letrass5.cl). Retóricamente, usa, además, el collage de diversos documentos de época, desde crónicas de navegantes, epitafios de tumbas, informes de derechos humanos hasta las líneas de messenger electrónico. A través de estos soportes, Formoso crea una voz y una memoria para cada uno de los muertos y una escena catatónica para él mismo encerrado en la cabina de un cibercafé.

La palabra poblador adquiere otra dimensión en la poesía de Christián Formoso. Ya no se trata tan sólo de aquel sujeto que no tiene casa y vive de allegado en hogares de familiares, o amigos, o en campamentos miserables. Formoso usa el significado antropológico, a saber, poblador como "habitante" (RAE, 1992), el que crea un hábitat para vivir. Y desde ahí examina toda la cultura de la zona de Punta Arenas para metaforizarla mediante la figura de la fosa. En esta poesía, fosa y cultura se vuelven equivalentes.

La primera fosa en Punta Arenas se abre con la llegada de la tripulación magallánica. Esta fosa está formada por los restos humanos que los indígenas lanzaron a la tripulación magallánica. El poema lo enuncia Antonio Pigafetta, el cartógrafo italiano que viajó con Hernando de Magallanes y que murió en su tierra natal. Formoso plantea una voz como transcripción de la crónica que hizo efectivamente Pigaffeta. La voz dada a este tripulante magallánico enuncia
Tuvimos por todo remedio quemar nuestras naves frente a la gran muralla (ilegible) y entonces de lo alto de la muralla comenzaron a arrojar los restos de unos sujetos $(\ldots)$ cuyas tripas semejaban una bandera (ilegible) y cuyos huesos dibujaban unos nombres que no supe descifrar. Mientras caían los (ilegible) frente a nosotros, se comenzaron a abrir los primeros sepulcros, las primeras islas (43-44).

En el poema se concibe la ciudad como el advenimiento de una frontera o muralla y la amenaza de muerte para quien la traspase, es decir, el castigo de la fosa. ${ }^{8}$ Los archivos de la fundación/fosa están 'ilegibles' en la ficcionalización de Formoso. Es decir, lleva al poema mismo el problema respecto a la escritura como medio de registro. En definitiva, Formoso hace entender que la memoria está ilegible y que por tanto, somos enfermos del mal de archivo, aquello que

\footnotetext{
${ }^{8}$ La leyenda sobre la fundación de Roma plantea que los gemelos Rómulo y Remo decidieron construir una ciudad en el mismo lugar donde los encontró la loba que los amamantó. Rómulo trazó un círculo que nadie podía cruzar sin sufrir la pena de muerte. Remo saltó sobre el círculo, violando la muralla. Rómulo lo mató (Grimal, 2009). Esta leyenda me sirve para vincular dos conceptos asociados a la ciudad: la muralla y la fosa, poetizados por Formoso.
} 


\section{Magda Sepúlveda}

Derrida definió como: "Una pulsión de agresión y de destrucción, ella no sólo empuja al olvido, a la amnesia, a la aniquilación de la memoria, sino que manda asimismo la borradura radical" (Derrida, 1997:19). La amnesia versa sobre los pobladores originarios, esos son los nombres que no se pueden descifrar.

Formoso da vida a un conjunto de voces espectrales que van contando la historia de Punta Arenas. Así pasan los personajes de la Colonia y del siglo XIX, como el teniente Miguel Cambiaso que se sublevó contra el presidente Manuel Montt y la suiza María Pittet ${ }^{9}$ que fue asesinada por militares que estaban relegados en 1877. La voz básica incorpora el inglés cuando aborda la época del ganado lanar. Para explicarse este procedimiento, no basta con indicar que Formoso es licenciado en letras inglesas. Esta voz está disputando con los ingleses que mataron indígenas para expulsarlos del territorio que necesitaban para el pastoreo. A partir de 1833, los ingleses se instalaron en las islas Falkland y desde ahí por toda la Patagonia, creando estancias cuyo fin productivo fue el llamado oro blanco. La economía decayó en 1920, tras la apertura del canal de Panamá. Antes de ese tiempo, la matanza de indígenas fue brutal. Formoso recorre las lápidas ubicadas cerca de las estancias y polemiza con las inscripciones referidas a los dueños de estas propiedades. Por ejemplo, el epitafio en las tumbas de los muertos de la estancia Caleta Josefina

This stone
was erected by their fellow employees
in memory of
Edward Williamson and Emilio Traslaviña
who were killed by indians
near San Sebastian
in January $16^{\text {th }} 1896$ (97).

Formoso recupera las inscripciones de las lápidas, pero cambia el sentido del epitafio. Mientras ella muestra a los indígenas como asesinos, Formoso exhibe la construcción de estancias como un proceso de asesinato mutuo, donde mueren tanto indígenas como empleados y estancieros. Formoso va buscando reconstruir el archivo perdido tras las tumbas. Incluso, considera casos en que el

\footnotetext{
${ }^{9}$ Ella formó parte de las familias suizas que emigraron a la Patagonia chilena tras los beneficios que ofrecía el Estado chileno a favor de producir una colonia agrícola y evitar la condición de colonia de relegamiento que estaba adquiriendo Magallanes. La otra mujer a quien Formoso le dedica especial atención es Sara Braun, pero tomando una distancia crítica con respecto a ella. Sara Braun, de origen ruso, se casó con un comerciante portugués que hizo gran fortuna gracias a la crianza de ovejas que instaló en el millón de hectáreas magallánicas que le regaló el gobierno chileno como parte de su programa de apoyo a los inmigrantes. En 1895, tras la muerte de su marido, ella finalizó el palacio donde vivió junto a su descendencia. Formoso realiza una polémica oculta con la prominencia museográfica que ella tiene. Ella y su banalidad aparecen en esta voz: "Que alguien con devoción / me peine los domingos / de mi victoria" (87). Para ella, no hay mal de archivo; entonces ahí Formoso instala la polémica.
} 
único archivo son los huesos. En esa situación, su retórica se asimila a la del lenguaje forense, lo cual sucede con las culturas aborígenes, donde la única escritura es el hueso

Inventario de los restos óseos humanos.

Fosa Isla Karukinka

Bolsa 75

Costilla izquierda, individuo joven 16 a 17 años, bien conservada; vértebras lumbares completas bien conservadas, vértebras torácicas bien conservadas, probablemente del mismo individuo. Bolsa 87

Mandíbula semi-completa, molares con leve desgaste.

Bolsa 77

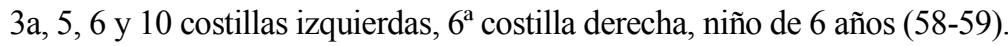

Desde la escritura de Formoso, la cultura humana es destrucción. Donde hay un monumento de cultura hay una fosa. Su intento poético es retornar a la vida y armar un cuerpo con los fragmentos. Tal como en 2666, de Roberto Bolaño, la posibilidad de aclarar las existencias de las vidas anónimas a partir de fragmentos está negada.

De esta manera, para Formoso, el exterminio de pobladores durante la dictadura está dentro de un continum humano que es la violencia. Los cementerios clandestinos de la dictadura se asemejan a las fosas sin nombre de los restos de nativos. Formoso asume como trabajo hablar del resto que va dejando la cultura, de ese archivo que se quiere hacer desaparecer de la historia oficial. Este deseo por publicitar ese otro archivo está puesto en las palabras de uno de los pobladores, amarrado con alambre y tirado al mar, que crea Formoso donde el que cayera no pudiera sino salir atado con alambres, (y) que lo que soñara desde ahora sería un sueño hermoso y lleno de sangre, y que yo sería mi sueño y su sueño serían todos los hijos de las poblaciones y las tomas y de los lugares que cientos de años antes fueron tomas y poblaciones y cementerios y que de ahora en adelante ese río que estaba escondido estaría a la vista de todos (39).

En la voz del poblador asesinado aparece el sueño, tal como en Zurita. Creo que esto tiene que ver con la suspensión de la realidad. Ha sido tan escasa la documentación sobre las poblaciones ${ }^{10}$ que parece que esa parte de la historia de Chile hubiera sido un sueño.

El extravío del archivo de los pobladores tiene eco en la situación actual de los habitantes de los márgenes citadinos. En la órbita del consumo, a los jóvenes populares les corresponde la droga. Así ocurre con los nuevos pobladores que habitan en cierta zona de Punta Arenas sector norponiente

Calles Rómulo

Correa, capitán

${ }^{10}$ Destaca en el levante del cine sobre poblaciones, el trabajo de Pablo Corro quien ha escrito sobre el filme documental Las Callampas (1957) de Rafael Sánchez quien fue profesor y fundador del Instituto Fílmico de la Pontificia Universidad Católica de Chile. 


\title{
Magda Sepúlveda
}

\author{
Guillermos, avenida \\ Circunvalación \\ Pasajes interiores: angostos \\ Terrenos ocupados por grupos \\ de jóvenes para beber \\ y drogarse, existencia \\ de basurales clandestinos \\ en los alrededores (226).
}

Formoso asume que todo poblamiento tiene la violencia como signo fundador y por ello busca, inventa y configura los archivos de esa agresión. En esa búsqueda, su poesía torna la mirada hacia los cementerios y las fosas en tanto archivos sobrevivientes al exterminio. Formoso escribe desde los vestigios que dejan las culturas, especialmente, en Punta Arenas.

En conclusión, los pobladores se transforman en una voz importante en la poesía publicada durante la transición. Su presencia es explicable en la medida que acontece su derrota o su muerte, precisamente, en ese periodo posdictatorial. Tanto José Ángel Cuevas y Raúl Zurita como Christian Formoso resienten esa comunidad perdida, con todo su poder de agente de cambio y su poder inclusivo de diversas identidades sociales. Los poetas recrean esa comunidad desde el sentimiento doloroso de la pérdida $\mathrm{y}$, al hacerlo, resisten el olvido.

$$
\begin{array}{r}
\text { Pontificia Universidad Católica de Chile* } \\
\text { Facultad de Letras } \\
\text { Departamento de Literatura } \\
\text { Avda.Vicuña Mackenna 4860, Macul, Santiago(Chile) } \\
\text { msepulvu@uc.cl }
\end{array}
$$

\section{BIBLIOGRAFÍA}

Barros, María José. “La posdictadura en la poesía de José Ángel Cuevas. La distopía del ex Chile". Ponencia presentada en el Congreso Extraordinario $30^{\circ}$ Aniversario SOCHEL. Valdivia: Universidad Austral, 2009.

Beverly, John. Subalteridad y representación: Debates en teoría cultural. Madrid: Iberoamericana-Vervuert, 2004.

Bianchi, Soledad. "Una meditación sobre una silla de paja: Desde Chile, José Ángel Cuevas. Una poesía en la época de la expansión global”, en Revista de crítica literaria latinoamericana 58. 159-173.

Brito, Eugenia. "Una aproximación a un texto inmenso: El cementerio más hermoso de Chile de Christian Formoso" en Letras s5, 2008. (Consulta: 20 de diciembre de 2008). http://www.letras.s5.com/cf020708.html

Corro, Pablo et al. Teorías del cine documental chileno (1957-1973). Santiago de Chile: Ediciones de la Pontificia Universidad Católica de Chile, 2007.

Cuevas, José Ángel. Restaurant Chile. Santiago de Chile: Calabaza del Diablo, 2005.

------ Diario de la ciudad ardiente. Santiago de Chile: LOM, 1998.

Poesía de la Comisión Liquidadora. Santiago de Chile: LOM, 1997. 
------ Proyecto de País. Santiago: América del Sur, 1994.

Derrida, Jacques. Mal de archivo: Una impresión freudiana. Valladolid: Trotta, 1997.

Formoso, Christian. El cementerio más hermoso de Chile. Santiago de Chile: Cuarto Propio, 2008.

Galindo, Óscar. "Marginalidad, subjetividad y testimonio en la poesía chilena de fines de siglo", en Revista de crítica literaria latinoamericana 58. 2002:193-213.

Garcés, Mario. Tomando su sitio: El movimiento de los pobladores de Santiago (19571970). Santiago de Chile: LOM, 2002.

Grimal, Pierre. Diccionario de mitología griega y romana. Barcelona: Paidós, 2009.

Jara, Víctor. La población. 1972. Textos de Alejandro Sieveking y Víctor Jara. Reedición a cargo de Carlos Fonseca. Santiago de Chile: Fundación Víctor Jara, 2001.

Lyotard, Jean Francois. La condición posmoderna. Informe sobre el saber. Madrid: Cátedra, 1984.

Nómez, Naín. "Pablo de Rokha y José Ángel Cuevas: De la nostalgia del mundo rural al sujeto de la ciudad marginal", en Alpha 31. Diciembre. 2010:175-194.

Otano, Rafael. Nueva crónica de la Transición. Santiago de Chile: LOM, 2006.

Parra, Violeta. "Me gustan los estudiantes". www. violetaparra.cl. Fundación Violeta Parra. Consultada el 26 de diciembre del 2010.

Salazar, Gabriel; Julio Pinto. Historia contemporánea de Chile III. Santiago de Chile: LOM, 2002.

Vekemans, Roger; Ismael Silva; Jorge Giusti. Hacia la superación de la marginalidad en América Latina. Santiago de Chile: Centro para el Desarrollo Económico y Social de América Latina, 1969.

Zalaquett, Cherrie. "José Ángel Cuevas: Versos libres con el rock del mundial y el 11 de septiembre. Entrevista. La Segunda. 25, octubre, 1989. Reproducida en www. letrass5.cl, 23 dic., 2010.

Zurita, Raúl. La vida nueva. Santiago de Chile: Universitaria, 1994. 